Article

\title{
Identifying the Influencing Factors on Investors' Investment Behavior: An Empirical Study Focusing on the Chinese P2P Lending Market
}

\author{
Xi Yang ${ }^{1,2}$, Wenjuan Fan ${ }^{1,2, *}$ and Shanlin Yang ${ }^{1,2}$ \\ 1 School of Management, Hefei University of Technology, Hefei 230009, China; xiyang_hfut@163.com (X.Y.); \\ shanlinyang_hfut@163.com (S.Y.) \\ 2 Key Laboratory of Minister of Education on Process Optimization and Intelligent Decision-Making, \\ Hefei 230009, China \\ * Correspondence: fanwenjuan_hfut@163.com
}

Received: 29 April 2020; Accepted: 11 June 2020; Published: 1 July 2020

\begin{abstract}
Our study explores the factors influencing investors' behavior in the peer-to-peer (P2P) lending market in China, and the relationships among them from the perspective of investors. The primary component analysis method was used to divide the P2P lending platforms into five categories. Then, a structural equation model was applied to analyze the interrelationship. Our results show that more exceptional operating ability, profitability, and security of the platform help to improve investor's investment behavior. Operation ability is the most significant influencing factor, which also influences other factors to different degrees. After the analysis of the results, we found that the security degree of $\mathrm{P} 2 \mathrm{P}$ lending platforms in China differs, and the risk due to the lack of bank depository for platforms is the most serious. In terms of the background, investors are less interested in the state-owned platforms compared to the bank- or listed-company-owned platforms, although the background strength of the state-owned platforms is more powerful.
\end{abstract}

Keywords: peer-to-peer (P2P) lending platform; uncertainty; investment behavior; green investments; principal component analysis; structural equation model

\section{Introduction}

Online peer-to-peer (P2P) lending refers to the practice of leading money from lenders to borrowers through online lending platforms. Participating in P2P lending generally includes the following steps. First, both borrowers and lenders need to register on the online lending platforms, and borrowers are required to provide certificates for credit checking, such as identity information, income and work certificates, credit reports, etc. Then, the P2P lending platform will check whether the borrower could meet the required standard. If so, the loan applications will be announced. Investors can check the borrower's credit through the platform, and offer loans if the credit is confirmed. The borrower must repay both the principal and the interest in accordance with the requirements specified in the loan contract. This P2P lending model was introduced in China in 2007. For the current P2P lending industries in China, both the size of the transaction and the number of participants have increased enormously after several years of rapid development. However, problems have also emerged over the years. According to the data provided by the Wangdaizhijia (WDZJ), there have been frequent accidents in the industry, and the number of problematic platforms has reached 900 since 2015. Thus, the whole P2P lending industry faces huge pressure, leading to 
negative public opinion. While investors' confidence has decreased, regulatory intervention has increased, with the industry beginning to hit a trough from its peak. During this turbulent period, the factors affecting investors' investment behaviors on P2P lending platforms have also undergone profound changes. We conducted a case study to explore the factors influencing investors' investment behavior on P2P lending platforms and the relationships among them. Furthermore, based on the analysis results, we describe the situation of the P2P investment network industry in China by discussing its characteristics and the existing problems, and provide some valuable references and suggestions for market participants.

P2P lending markets in China (PMC) have gone through different development stages compared to developed countries, and thus the present situation of platform development has distinct Chinese characteristics compared to developed countries. The P2P lending market is mature and stable in developed countries, in which the market has the characteristics of rational social expectation, a perfect regulatory system, a stable transaction scale and a high degree of industry concentration. In the P2P lending market of the United States, the main firms are Lending Club, Prosper and SoFi, of which Lending Club and Prosper are the two oldest platforms with the largest market shares, and SoFi focuses on the housing mortgage loan business to gain a market share. In the UK, the market share of the P2P lending market is dominated by Zopa, Funding Circle, Rate Setter and Market Invoice. The personal loan market is dominated by Zopa and Rate Setter, the enterprise loan market is mainly funded by Funding Circle, and the invoice market is dominated by Market Invoice.

In China, the P2P lending industry is undergoing a transition from peak to trough, which is characterized by lower social expectations, slower trading volumes and formal regulatory intervention. In 2016, the whole industry entered a reformation period and the government introduced a series of policies to speed up this process; for example, within a certain time, all P2P lending platforms must regulate their own operation, cancel the current money products, promote capital supervision systems, and close offline stores, etc. This process has accelerated the industry evolution and raised the threshold required to enter the industry. With the formation of the new competition pattern, the industry differentiation becomes obvious and the industry concentration is further improved. On the one hand, large platforms with deep backgrounds, normative services, sophisticated risk control, and high visibility have attracted the largest number of investors. On the other hand, small- and medium-sized platforms with weak strength, weak risk control, irregular business, and a high rate of bad accounts face great pressure to survive, with some leaving the market.

With a difficult transition, the P2P lending industry in China is now in a more rational development stage, and the traditional financial institutions have begun to enter the P2P lending ecosystem, which plays a vital role in the industry regarding asset security and efficient service. Capital risk is gradually inclining in the later rounds for mature platforms, and the Matthew effect of industry development is also emerging. In this stage, the industry standard has improved, the compliance cost of the platform has increased, and P2P has become an important node of the financial network.

The changes of the overall investment environment have resulted in new problems, how to select investment problems and how to identify factors influencing the development of the platform and investors' decisions. Because the P2P lending industry in China is in the early stages of development, the transparency of $\mathrm{P} 2 \mathrm{P}$ lending platforms is generally low and the information is fragmented. Therefore, when the investors choose the platform, the relevant assessment provided by a third-party information platform is an important reference. This can reflect the investment behavior to a certain extent. Two main third-party information platforms rate P2P lending platforms in the Chinese P2P lending market: WDJZ and P2Peye. Because there are huge differences in the evaluation perspective of the two third-party information platforms, and neither is based on the perspective of investors, the degree of investment willingness is very limited. Besides, differentiated evaluation results affect investors' selection decisions on the platform to some extent. 
The differences in the evaluation systems of the two third-party information platforms are reflected in four aspects: the platform sample selection, the platform index system, the index quantification standard, and the index classification basis. The index system of WDJZ mainly includes online time, location, volumes, popularity, leverage, dispersion, liquidity, and transparency, a total of eight indicators; it finally evaluates P2P lending platforms using the development index developed by its index system. The index system of P2Peye includes repayment, cash flow, rate, operation, period, regionalism, investment, loan, and liquidity, a total of nine indicators; it finally evaluates P2P lending platforms with a grade rating and score. The specifications of the index systems are shown in Tables 1 and 2, respectively.

Table 1. The index system of WDJZ.

\begin{tabular}{|c|c|}
\hline Indicators & Explanations \\
\hline Online time & Index for measuring the operating time of the platform. \\
\hline Location & Index indicating the regional characteristics of the platform. \\
\hline Volumes & Index for measuring volumes. The higher the integration, the higher the volume. \\
\hline Popularity & $\begin{array}{l}\text { Index for measuring the number of investors and borrowers. The higher the score, } \\
\text { the greater the investment and borrowing. }\end{array}$ \\
\hline Leverage & $\begin{array}{l}\text { Index for measuring the risk tolerance. The higher the score, the lower the potential } \\
\text { leverage of the platform and the stronger the risk tolerance. }\end{array}$ \\
\hline Dispersion & $\begin{array}{l}\text { Index for measuring the dispersion of funds on borrowing and investment. The higher the } \\
\text { score, the more diversified the platform's investment and borrowing and the lower the } \\
\text { platform operation risk. }\end{array}$ \\
\hline Liquidity & $\begin{array}{l}\text { Index for measuring the investors' recovery time. The higher the score, the shorter the time } \\
\text { for the investment in the principal. }\end{array}$ \\
\hline Transparency & $\begin{array}{l}\text { Index for measuring the information transparency. The higher the score, the more open the } \\
\text { platform information and the more transparent the platform. }\end{array}$ \\
\hline
\end{tabular}

Table 2. The index system of P2Peye.

\begin{tabular}{|c|c|}
\hline Indicators & Explanations \\
\hline Repayment & $\begin{array}{l}\text { Index for measuring the amount of pressure to pay back in the last quarter. The larger the } \\
\text { exchange rate, the greater the pressure on the platform to pay back in the last quarter. }\end{array}$ \\
\hline Cash flow & Index for measuring the growth of the platform and balancing the security of the platform. \\
\hline Rate & $\begin{array}{l}\text { Index for measuring the security of the platform. The higher the interest rate, the higher } \\
\text { the risk the platform will take and the lower the profit for the same audit cost. }\end{array}$ \\
\hline Operation & Index for measuring the fund management and operation ability of the platform. \\
\hline Period & Index for measuring platform security and brand awareness. \\
\hline Regionalism & Index for measuring the maturity of the network loan industry in the region. \\
\hline Investment & $\begin{array}{l}\text { Index for measuring the dispersion of investment. The higher the investment index, } \\
\text { the higher the risk concentration. }\end{array}$ \\
\hline Loan & $\begin{array}{l}\text { Index for measuring the dispersion of the platform's loan. The lower the loan index, } \\
\text { the less the platform affected by a single borrower's default. }\end{array}$ \\
\hline Liquidity & $\begin{array}{c}\text { Index for measuring the liquidity of the platform's funds. The higher the flow, the lower } \\
\text { the liquidity. }\end{array}$ \\
\hline
\end{tabular}

From the comparison between the evaluation systems of the two third-party information platforms, it is obvious that they assess P2P platforms from different perspectives based on their own understanding 
of the industry. Because each has its own algorithm for index calculation, their final ratings of the same P2P lending platform are different, which may seriously affect investors' judgment when choosing platforms to invest in.

To evaluate the effects of these differences, this study selected $42 \mathrm{P} 2 \mathrm{P}$ lending platforms evaluated by both evaluation systems. The grades of these platforms are distributed among A+, A, B+, and B in the P2Peye index system. In WDJZ, their scores range from 40.29 to 74.14 . Although the index systems are different, the level or position of the same platform in the two index systems should be similar. As the hierarchy of P2Peye is already clear, we needed a method to divide the WDJZ ranking into four corresponding levels according to the distribution of its data before comparing them.

$\mathrm{K}$-means is a cluster analysis method usually used to group a dataset into distinct subgroups when these are not previously known [1,2]. K-means is an appropriate method to apply in this case. The first step is to define a set of initial cluster centers deriving from the data, then assign each one to the most similar cluster. Each time a sample is assigned, the cluster center of the cluster will be recalculated according to the existing objects in the cluster. This process is repeated until either the maximum number of iterations is reached or the difference between two consecutive iterations does not exceed a specified threshold. Using K-means, the target platform was classified into four categories based on the WDZJ score, as shown in Table 3. The comparison of the rating levels for the platforms in WDZJ and P2Peye is shown in Figure 1.

Table 3. The classification results of the platform in WDZJ.

\begin{tabular}{ccccc}
\hline & \multicolumn{4}{c}{ Clusters } \\
\cline { 2 - 5 } & $\mathbf{1}$ & $\mathbf{2}$ & $\mathbf{3}$ & $\mathbf{4}$ \\
\hline Cluster center & 68.16 & 58.69 & 49.76 & 45.03 \\
\hline Sample size & 6 & 9 & 16 & 11 \\
\hline
\end{tabular}

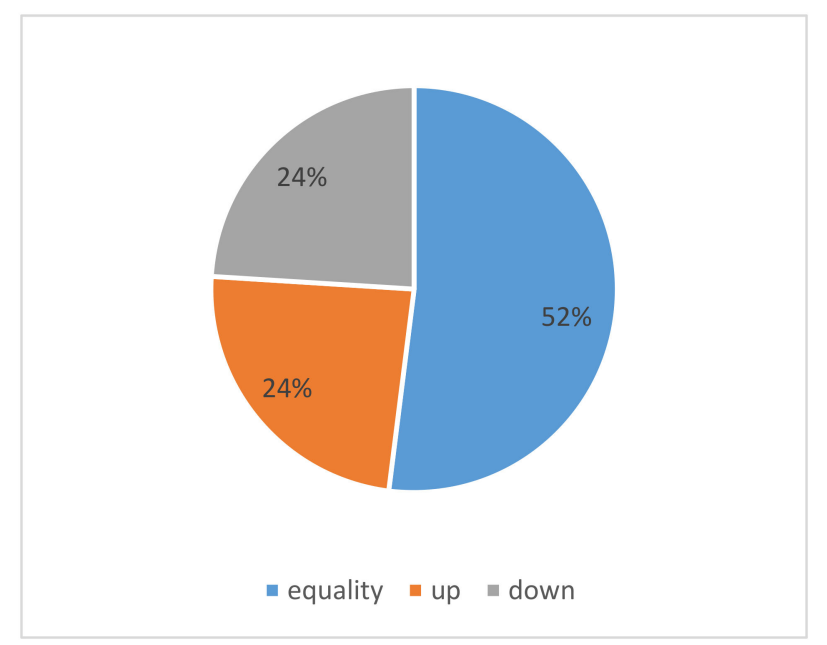

Figure 1. The comparison of rating levels between the WDZJ and P2Peye platforms.

Figure 1 shows that $48 \%$ of the P2P platforms are evaluated as having a different level in the two evaluation systems; among them, the greatest difference reached two levels, which has a great impact on the judgment of ordinary investors.

Facing the new investment environment, this paper mainly addresses the above problems and contributes as follows. First, our work presents a novel study that compared the evaluation systems of 
P2P lending platforms established by third-party information platforms of the P2P lending market in China and showed that the difference might affect the investment decisions of investors. Second, to the best of our knowledge, the data for the P2P lending platforms in China are integrated into five categories, and the P2P lending market network in China was analyzed for the first time. Third, the development of the P2P lending industry in China is revealed through the analysis of the data of P2P lending platforms for the first time. Fourth, we have two interesting and significant findings: the operation ability of P2P lending platforms has a negative influence on the security of P2P lending platforms, and the resources of $\mathrm{P} 2 \mathrm{P}$ lending platforms have a negative influence on the investment behavior of investors. Furthermore, the association rules were used to analyze the possible cause of these two phenomena. Finally, based on the research results of this study, relevant suggestions are given to the participants in the P2P lending market in China, which provide a reference for the healthy growth of the entire industry.

This paper is structured as follows. Section 2 is the literature review. Section 3 presents the variable definitions, and the process of variable measurements and formations. Section 4 provides the research hypotheses of this study, in which the establishment of the system and the hypotheses are described, and the preliminary standardized structure diagram indicating the influencing factors on investment platform selection is also constructed. Section 5 presents an empirical analysis. The development status of the P2P lending industry in China is revealed by data analysis and the hypotheses were verified. This article also discusses the causes of abnormal phenomena by using association rules. Section 6 discusses the obtained results and Section 7 concludes our work.

\section{Literature Review}

Most of the existing research on the P2P lending industry can be classified into four categories: personal credit assessment on borrowers, analysis of P2P lending behavior, social network and interpersonal influence on borrowing, and the external factors affecting the development of the P2P lending industry. However, there is little research on the influence factors on investment behavior for P2P lending platforms. Therefore, in this section, we review the studies on the other four aspects.

In terms of personal credit assessment, through the analysis of the data set of the Lending Club publicly available loan applications dataset for 2013-2015, Kumar et al. used ensemble machine learning algorithms and preprocessing techniques to find the factors that play key roles in the credit risk prediction [3]. From the perspective of solving the portfolio optimization problem with boundary constraints, Guo et al. established a risk assessment model for $\mathrm{P} 2 \mathrm{P}$ online lending, which can greatly improve the investment performance of the platform [4]. Serrano-Cinca outlined with research for profit scoring. Unlike previous research ideas based on default risk, the author focuses on assessing the expected profitability of P2P loan investment and points out that $\mathrm{P} 2 \mathrm{P}$ lending is not currently a fully efficient market [5]. Xia et al. built a cost-sensitive boosted tree loan evaluation model. This transforms the portfolio optimization problem into an integer linear programming problem and measures the expected profitability through the annualized rate of return (ARR) [6].

In terms of P2P lending behavior analysis, Puro introduced a Borrower Decision Aid system by using data from Prosper, which can help borrowers to quantify their investment decisions [7]. Tan et al. investigated how charge-off and prepayment risks are reflected in funded loans [8]. Jiang et al. found that the investors' herding behavior is positively correlated with the P2P lending platforms' market share and the cumulative amount funded, but negatively correlated with the operation time [9]. Yum et al. confirmed that investors' judgment will be influenced by other investors when information on P2P lending platform is extremely limited, but when more information is transmitted through the market they switch to their own judgment. When borrowers' creditworthiness is in doubt, they may communicate directly with investors in order to maintain a good reputation [10]. Emekter et al. analyzed the factors affecting 
P2P personal lending behavior based on data from the Lending Club. The research results show that the debt-to-income ratio, revolving line utilization, credit grade and Individual Credit scores in the United States (FICO) score play important roles in loan defaults. The likelihood of default increases with the borrower's credit risk, and higher interest rates charged by risky borrowers are not enough to compensate for the higher probability of a loan default [11].

Analysis of lending behavior is more relevant to the Chinese market due to its particularities. Shen et al. used Key Points Approximate Fitting (KPAF) algorithm to preprocess data to identify different investment strategies based on the data from Paipaidai (PPDAI) platform in China. The KPAF algorithm contributes to a better accuracy of clustering [12]. Zhang et al. studied investment proposal recommendations for investors in the P2P lending market. The results show that the performance of the recommendation algorithm has important influence on the suggestion, and the performance of cooperative filtering algorithms is different in P2P lending compared with some other areas [13]. Xu et al. found that the proposed feature set in the widely adopted classification methods outperforms the baseline feature set. By analyzing the trading characteristics of defaulters, the potential risk of investors can be effectively reduced [14].

In terms of social network and interpersonal influence on borrowing, Lin et al. found that the friendship between the two sides of the transaction can significantly improve the quality of the transaction, including the success rate of financing and the interest rate of the loan [15]. Liu et al. investigated how friendship relationships work in the P2P lending market. By analyzing the decisions of investors, they found that trading behavior between friends may mislead other potential investors' investment decisions and lead to herd behavior to some extent [16]. Jiang et al. analyzed trust management in the P2P lending industry from the aspects of trust domain, attribute-based recommended trust, trust evaluation and trust improvement. They found that traders can cooperate with each other to enhance their trust and thus form interest groups to obtain more opportunities to share resources [17]. Since the relationship between the P2P lending industry and social networks in China are not as close as in the United States, some of the existing research results cannot be applied in the Chinese market, and the related research for China is rare from this perspective; thus, its achievement is very limited. For example, Guo et al. explored the impact of social data on credit scores using microblogs under the microblogging setting [18].

In terms of the external factors affecting the development of the P2P lending industry, studies in this field do not consider other aspects. Moreover, due to differences in the development levels of the P2P lending market in China and developed countries, our research on these two different markets also presents different characteristics and directions. Chen et al. discussed the possible impact of individuals' group social capital on the P2P lending market. The research results show that the relational social capital and the general group social capital have completely different effects on the borrower. The structural social capital of borrowers is negatively correlated with their transaction efficiency [19]. Wang et al. established Fuzzy Support Vector Machine algorithm with Region Information (FSVM-RI) model by using a fuzzy Support Vector Machine (SVM) algorithm with regional information to evaluate risk platforms in the Chinese P2P lending market. The results show that this method is superior to other methods in analyzing data with missing values and outliers [20]. Pingfan et al. found that the operational efficiency of P2P lending platforms is negatively correlated with the development level of the cities where they are located. This means that the development of the P2P lending industry can to some extent solve the problem of resource allocation caused by regional development imbalance [21]. Xu et al. analyzed the different influences of social capital and other factors on the P2P lending industry in China and the United States, and the research results showed that the importance of P2P lending industry in different countries was greatly different. Social capital has a significant impact on the Chinese market in terms of being funded, while it has a relatively significant impact on interest rates in the US [22].

Through this literature review, it is clear that most of the research on the P2P lending industry is from the perspective of borrowers, and the research on platform selection is very limited. Wei highlights that 
this is because the P2P lending industry in developed countries is relatively mature, and the oligopolistic market pattern has basically been established, and thus investors can choose a platform relatively easily. However, the current situation in the P2P lending industry in China is quite special, since investors need to choose a good P2P lending platform among many at different levels [23]. Wei et al. analyzed the risk contagion mode of the $\mathrm{P} 2 \mathrm{P}$ lending market in China from two aspects: direct risk contagion and indirect risk contagion. The research results show that the contagion intensity of indirect risk is much greater than that of direct risk. Meanwhile, the information asymmetry and the superposition of media effect will aggravate the contagion degree of risk to some extent [24]. In the face of such situations, investors often make irrational decisions because of their risk awareness, risk tolerance and relative lack of professional knowledge.

The current situation of the P2P lending market in China is different from developed countries, with limited research on the platform selection. Thus, we studied the influencing factors of investors platform selection from the perspective of investors, analyzed the influencing degree of different factors on investors decision-making process and the relationship between the factors, and then achieved the purpose of providing a reference for investors on P2P lending platform selection.

\section{Variable Definition}

\subsection{The Measurement of Investement Behavior}

The evaluation systems of the aforementioned two third-party information platforms generally prefer platform safety assessment, and, in most cases, are not from the perspective of investors and thus cannot help investors make investment decisions. Therefore, a comprehensive factor analysis is needed to measure the investors' investment behavior that can reflect the potential of the platform.

This study selected the evaluation system of the Chinese P2P lending industry rating report in 2016 to measure the investment behavior. The report was published by rong360 and Renmin from the University of China, and measures the investors' investment behavior in P2P lending platforms. It considered six dimensions: background strength, risk identification, operation ability, information disclosure, standardization, and user experience. The quantitative indicators are graded into nine levels: $\mathrm{A}+, \mathrm{A}, \mathrm{A}-, \mathrm{B}+, \mathrm{B}, \mathrm{B}-, \mathrm{C}+, \mathrm{C}$, and C-. In addition to platform security, the platform can also be evaluated from the perspective of user experience, which comprehensively reflects investors' investment behavior. However, the report does not give a specific relationship between the six dimensions and the investors' investment behavior. In addition, the influencing factors considered in the report and this study are different, and thus the related content are analyzed in detail below. We selected $82 \mathrm{P} 2 \mathrm{P}$ lending platforms with complete data, of which $10 \mathrm{P} 2 \mathrm{P}$ platforms were assessed as A or A-, accounting for $12.2 \%$ of the total samples; 40 were assessed as B+, B or B-, accounting for $48.78 \%$ of the total sample; and 32 were assessed as $\mathrm{C}$ or $\mathrm{C}-$, accounting for $39.02 \%$ of the total sample. This distribution is basically consistent with investors' expectations of China's P2P lending industry.

\subsection{Determining the Influencing Factors}

To determine the specific factors that affect investment decisions, we had to generalize and integrate existing platform data. We collected all available data about P2P lending platforms to extract possible influencing factors, trying to understand the current situation of the P2P lending market in China. According to the evaluation system of the two third-party information platforms, 24 indicators were selected: bank depository, Internet Content Provide (ICP) license, venture capital, guild, public equity, third-party credit, volumes, investor, borrower, rate, final maturity, object quantity, registered capital, object time, pending loan, time weighted volume, pending loan for 60 days, top 10 investment proportion, 
top 10 loan proportion, per capita loan, leverage, per capita investment, and operation time. Since there are no $\mathrm{A}+$ and $\mathrm{C}+$ levels in the investment behavior index of all sample platforms, only the remaining seven levels were assigned. The assignment rules for the different indicators are shown in Table 4 .

Table 4. Assignment rules for the different indicators.

\begin{tabular}{cccc}
\hline Variable & Assignment Rules & Variable & Assignment Rules \\
\hline Investment Behavior & $\mathrm{A}, 7 ; \mathrm{A}-, 6 ; \mathrm{B}+, 5 ; \mathrm{B}, 4 ; \mathrm{B}-, 3 ; \mathrm{C}, 2 ; \mathrm{C}-, 1$ & Bank Depository & Yes, $1 ; \mathrm{No}, 0$ \\
\hline Background & $\begin{array}{c}\text { Bank-owned Platform, } 4 ; \\
\text { Listed-company-owned Platform, 3; } \\
\text { State-owned Platform, 2; } \\
\text { Private-owned Platform, } 1\end{array}$ & Third-Party Credit & Yes, $1 ;$ No, 0 \\
\hline Venture Capital & Yes, $1 ;$ No, 0 & ICP License & Yes, $1 ;$ No, 0 \\
\hline Guild & Yes, $1 ;$ No, 0 & Public Equity & Yes, $1 ;$ No, 0 \\
\hline
\end{tabular}

Principal Components Analysis (PCA) can reduce the data complexity effectively without losing much information. It is able to build robust models to find linear combinations of variables that can best capture the variance of the entire set, where the components are orthogonal to each other. By using PCA to extract information from 24 variables, multiple correlated variables were placed into a new including factor through linear combination. This not only preserves the main information of the original variables, but also describes the characteristics of different factors more effectively. The calculation results are shown in Tables 5-7.

Table 5. Kaiser-Meyer-Olkin (KMO) and Bartlett's Test.

\begin{tabular}{cc}
\hline Kaiser-Meyer-Olkin Measure of Sampling Adequacy & $\mathbf{0 . 6 3 7}$ \\
\hline Bartlett's Test of Sphericity Approx. Chi-Square & 2677.158 \\
\hline Df & 276 \\
\hline$p$-value & 0.000 \\
\hline
\end{tabular}

Table 6. Total variance explained.

\begin{tabular}{ccccccc}
\hline \multirow{2}{*}{ Component } & \multicolumn{3}{c}{ Initial Eigen Values } & \multicolumn{2}{c}{ Extraction Sums of Squared Loadings } \\
\cline { 2 - 7 } & Total & \% of Variance & Cumulative \% & Total & \% of Variance & Cumulative \% \\
\hline 1 & 7.523 & 31.346 & 31.346 & 7.523 & 31.346 & 31.346 \\
\hline 2 & 2.524 & 10.515 & 41.861 & 2.524 & 10.515 & 41.861 \\
\hline 3 & 1.995 & 8.311 & 50.172 & 1.995 & 8.311 & 50.172 \\
\hline 4 & 1.752 & 7.300 & 57.472 & 1.752 & 7.300 & 57.472 \\
\hline 5 & 1.490 & 6.207 & 63.680 & 1.490 & 6.207 & 63.680 \\
\hline
\end{tabular}


Table 7. Component matrix.

\begin{tabular}{|c|c|c|c|c|c|}
\hline & \multicolumn{5}{|c|}{ Component } \\
\hline & 1 & 2 & 0.03 & 4 & 5 \\
\hline Background & 0.064 & 0.230 & 0.242 & 0.503 & -0.112 \\
\hline Bank Depository & -0.110 & -0.033 & -0.235 & 0.068 & 0.683 \\
\hline ICP License & 0.116 & -0.015 & -0.206 & 0.477 & 0.126 \\
\hline Venture Capital & 0.250 & -0.052 & -0.011 & 0.001 & 0.102 \\
\hline Guild & 0.308 & 0.014 & 0.102 & 0.183 & 0.724 \\
\hline Public Equity & 0.180 & -0.067 & -0.104 & 0.673 & -0.171 \\
\hline Third-Party Credit & 0.204 & -0.470 & -0.006 & -0.189 & 0.486 \\
\hline Volumes & 0.833 & 0.422 & -0.064 & 0.029 & 0.050 \\
\hline Investor & 0.683 & -0.055 & -0.641 & 0.066 & -0.060 \\
\hline Borrower & 0.871 & -0.322 & 0.141 & -0.040 & -0.091 \\
\hline Rate & -0.092 & -0.655 & -0.030 & 0.213 & 0.069 \\
\hline Final Maturity & 0.595 & -0.185 & 0.141 & -0.134 & 0.063 \\
\hline Object Quantity & 0.860 & -0.274 & 0.073 & -0.096 & -0.027 \\
\hline Registered Capital & 0.268 & 0.039 & 0.310 & 0.616 & 0.004 \\
\hline Object Time & -0.606 & 0.308 & -0.111 & 0.211 & 0.109 \\
\hline Pending Loan & 0.879 & 0.371 & -0.024 & -0.016 & 0.011 \\
\hline Time Weighted Volume & 0.912 & 0.237 & 0.033 & -0.018 & 0.025 \\
\hline Pending Loan For 60 Days & 0.813 & 0.467 & -0.092 & 0.067 & 0.052 \\
\hline Top 10 Investment Proportion & -0.119 & -0.055 & 0.738 & -0.132 & 0.144 \\
\hline Top 10 Loan Proportion & -0.627 & 0.241 & -0.231 & -0.066 & 0.282 \\
\hline Per Capita Loan & -0.607 & 0.623 & -0.223 & 0.063 & 0.138 \\
\hline Leverage & 0.697 & 0.357 & -0.207 & -0.392 & 0.024 \\
\hline Per Capita Investment & 0.016 & 0.521 & 0.734 & -0.057 & 0.132 \\
\hline Operation Time & 0.523 & -0.248 & 0.091 & 0.232 & 0.136 \\
\hline
\end{tabular}

As shown in Tables 5 and 6, the value of Kaiser-Meyer-Olkin (KMO) is 0.637, the significance probability of Bartlett's test is 0.5 , the highest value of the main components is $>1.4$, and the cumulative explanation of the total variance is $63.68 \%$, which conforms to the standard of PCA. The selected 24 variables were integrated into five principal components according to the weights, and the composition structure of each principal component and the proportion of each variable in the five main components are presented in Table 7. Referring to the evaluation system of the two third-party information platforms, we can summarize the five main components as the five influencing factors.

The variables in the first principal component (F1) include volumes, borrower, object quantity, pending loan and time weighted volume. These are all important variables for measuring the operation ability of the P2P lending platform, thus the influencing factors reflect the operation ability of the P2P platforms.

The variables in the second principal component (F2) include per capita loan and rate. Both are important variables for measuring the profitability of the P2P lending platform, thus the influencing factors reflect the profitability of the P2P platforms. 
The variables in the third principal component (F3) include investor, top 10 investment proportion and per capita investment. These are all important variables for measuring the popularity of the P2P lending platform, thus the influencing factors reflect the popularity of the P2P platforms.

The variables in the fourth principal component (F4) include public equity and registered capital. Both are important variables for measuring the resources of the P2P lending platform; thus, the influencing factor reflects the platform resources of the P2P platforms.

The variables in the fifth principal component (F5) include bank depository and guild. Both are important variables for measuring the security of the P2P lending platform; thus, the influencing factor reflects the security of the P2P platforms.

To verify the effectiveness of the influencing factors, the results of the PCA were used to calculate the comprehensive factor score as follows:

$$
\mathrm{F}=7.523 \mathrm{~F}_{1}+2.524 \mathrm{~F}_{2}+1.995 \mathrm{~F}_{3}+1.752 \mathrm{~F}_{4}+1.49 \mathrm{~F}_{5}+7.523+2.524+1.995+1.752+1.49
$$

The results of analyzing the comprehensive factor scores and investment behavior using linear regression are shown in Table 8:

Table 8. Coefficients.

\begin{tabular}{|c|c|c|c|c|c|}
\hline \multirow{2}{*}{ Model } & \multicolumn{2}{|c|}{ Unstandardized Coefficients } & \multirow{2}{*}{$\begin{array}{c}\text { Standardized Coefficients } \\
\text { Beta }\end{array}$} & \multirow{2}{*}{$t$} & \multirow{2}{*}{ Sig. } \\
\hline & B & Std. Error & & & \\
\hline 1 (Constant) & 1.666 & 0.242 & & 6.890 & 0.000 \\
\hline $\mathrm{F}$ & 0.089 & 0.011 & 0.675 & 8.194 & 0.000 \\
\hline
\end{tabular}

From the results, it can be concluded that the coefficients of constant and $\mathrm{F}$ are both significant and the beta coefficient is positive, indicating that the comprehensive factor score is positively correlated with the investment behavior, and thus the validity of the factors was verified. In conclusion, these five influencing factors reflect the various influencing aspects of investors' consideration when selecting P2P platform. Furthermore, this paper puts forward eight hypotheses regarding the investor's platform selection behavior based on these influencing factors.

\section{Research Hypothesis}

\subsection{The Impact of the Profitability on Investment Behavior}

As a part of Internet financing, the P2P lending industry has a relatively high return on investment and provides convenient financing channels. According to the Chinese P2P lending industry rating report, nearly $50 \%$ of investors focus on the profitability of the P2P lending platforms when choosing to invest. More than $60 \%$ of investors target yields between $10 \%$ and $15 \%$, while about $3 \%$ of investors prefer a yield of $20 \%$, and around $23 \%$ are more likely to invest in those platforms with yield below $10 \%$ [25]. Higher yields indicate higher risk, particularly in China, where the P2P lending industry is less developed. Along with the process of industry integration, the average yield of the whole industry has been reduced and is gradually stabilizing at a reasonable level. Investors gradually become rational when investing through P2P platforms. They tend to choose those platforms with good operation to ensure the safety and sustainability of investment income. Although high return is no longer the only aspect on which investors focus, the rate of return on P2P lending platforms is still substantial compared to other investment channels and remains a huge attraction for investors. Therefore, based on the above analysis, the following hypothesis is put forward: 
Hypothesis 1 (H1). The profitability of a P2P lending platform has a positive influence on the investment behavior of investors. P2P lending platforms with higher profitability are more attractive to investors.

\subsection{The Impact of the Security Level on Investment Behavior}

In the Chinese P2P lending market, the security of P2P lending platforms is a top priority for investors. Because of the serious information asymmetry that exists between the P2P lending platform and the investors, the latter party can only investigate the P2P platforms through channels such as the media, network information and third-party information platforms when considering whether to invest. Therefore, it is hard for them to know the actual level of risk control and security of the platform. Thus, when investors assess the security level of a P2P lending platform, they tend to make judgments based on information such as whether the platform has joined the industry association, whether it has a bank depository, whether it collaborates with a third-party credit agency, etc. These judgment methods are indeed intuitive and effective when limited information is available, especially after the regulatory authority implements a policy that P2P platforms must have bank depository business. As banks have requirements in capital depository system access, docking platforms must satisfy the standards for risk control mode, the registered capital, the shareholders background, operating conditions and policy compliance, etc. This policy effectively prohibits $\mathrm{P} 2 \mathrm{P}$ lending platforms with security risks. It effectively enhances the enthusiasm of the P2P platform investors. Therefore, based on the above analysis, the following hypothesis is put forward:

Hypothesis 2 (H2). The security of a P2P lending platform has a positive influence on the investment behavior of investors. P2P lending platforms with higher security are more attractive to investors.

\subsection{The Impact of the Platform Resources on Investment Behavior}

In the Chines P2P lending industry, the social capital of P2P lending platforms cannot be ignored. $\mathrm{Xu}$ et al. pointed out in their research that the importance of P2P lending industry in different countries was greatly different. Social capital has a significant impact on the Chinese market in terms of being funded, while it has a relatively significant impact on interest rates in the US [20]. In the Chinese P2P lending market, the more resources the $\mathrm{P} 2 \mathrm{P}$ lending platform has, the more advantages it has in terms of normative, transformational and operational levels compared to other platforms, and investors will be more secure in their investments. As a result, investors often pay close attention to platform resources when making a platform choice, and nearly $70 \%$ of investors will study the platform's shareholders, registered capital and background. Therefore, based on the above analysis, the following hypothesis is put forward:

Hypothesis 3 (H3). The resources of a P2P lending platform have a positive influence on the investment behavior of investors. P2P lending platforms with stronger resource are more attractive to investors.

\subsection{The Impact of the Operation Ability on Investment Behavior}

As the main body of investment options, the operating ability of a P2P lending platform is not only an important factor when investors choose investment platform, but also has great influence on the platforms from aspects including profitability, security, resources, etc. In the Chinese P2P lending market, the operating ability of a platform is generally measured in three dimensions: the volume, activity and cash flow. For example, on the third-party platform P2Peye, the daily average cumulative transaction volume, i.e., the ratio of the accumulated transaction amount to the online time of the platform, measures the operation ability. In the Chinese P2P lending industry, rating report, volumes, borrower, investor, final maturity, object time, pending loan, per capita loan, etc., measure this. A P2P lending platform with 
strong operation ability often has abundant resources; a strong risk control system; obvious advantages in trading volume, brand credibility and investment capital inflow; and can more easily obtain financing in financial markets. On the one hand, it will further enhance the funding strength, risk resistance and background of the platform, and effectively improve the confidence of investors. On the other hand, the industry resources can be used to expand the platform business, develop new project channels and so on.

In terms of the impact on profitability, as an industry with high ROI, the P2P lending industry is often accompanied by high risk, especially in the Chinese P2P lending market in this early stage of development. Among the problematic P2P lending platforms, about $60 \%$ have ethical risks, such as missing links, running roads and fraud, that are higher than operational risks. These platforms often induce investors' investment with high returns, and, when they gain a lot of money in a short term, they quickly withdraw from the market, causing heavy loss for investors. After a series of such vicious incidents, both market and investors have become aware of such platforms. For example, in the evaluation system of P2Peye, security is investigated from the perspective of the platform, and it does not reflect the benefits that the platform brings to the investors. Although the rationality of this practice remains to be discussed, it also reflects the fact that the current investors focus on capital security rather than the return on investment. In this context, a platform with strong operating ability tends to keep yields within a safe range considering the long-term development of the platform. Although this leads to a low yield compared to the average level of the industry, this kind of market is more rational and investors' financial security is more secure.

The operating ability of a P2P lending platform influences its security in many aspects. As a mode of credit loan, the technical threshold of online credit collection for P2P lending is very high compared to the offline auditing of traditional credit modes. The platforms with strong operation ability tend to pay more attention to the security for sustainable development, and can build a perfect risk control system. In the early days of the Chinese P2P lending industry, many unskilled platforms flooded the market. Most of them no longer exist due to security issues, while those platforms with risk control systems have developed well. In addition, the platforms with strong operation ability have some advantages in accessing some security measures. For example, in the case of a bank depository, the bank mainly examines the qualification, core team, and operating ability of the platforms.

The P2P lending platforms with strong operation ability are more attractive to capital, and the platform resources are often very strong. Compared to individual investors, the capital investment industry has a more detailed understanding of the P2P platforms and is more likely to invest in platforms with well-established systems, professional techniques, and operational ability. After obtaining the support from the capital, the P2P lending platforms on the one hand gain more and better development resources, and, on the other hand, they must constantly upgrade their technical and management ability to operate these resources. With the continuous improvement of operation ability, the P2P lending platforms will gain more and more capital, and the resources will be strengthened at the same time.

Therefore, based on the above analysis, the following hypotheses are put forward:

Hypothesis 4 (H4). The operation ability of a P2P lending platform has a positive influence on the investment behavior of investors. P2P lending platforms with stronger operation ability are more attractive to investors.

Hypothesis 5 (H5). The operation ability of a P2P lending platform has a negative influence on the profitability of P2P lending platforms. The stronger is the operation ability of the platform, the stronger is the control ability of risk, and the profitability of the platform will naturally decrease accordingly. 
Hypothesis 6 (H6). The operation ability of a P2P lending platform has a positive influence on the security of P2P lending platforms. The stronger is the operation ability of the platform, the higher is the technical level, and the security of the platform will naturally increase accordingly.

Hypothesis 7 (H7). The operation ability of a P2P lending platform has a positive influence on the platform resources. A platform with strong operational capability has stronger financial strength and listing prospect, which is more attractive to capital, and its platform resources tend to be very strong.

\subsection{The Impact of the Popularity on Investment Behavior}

Behavioral finance theory points out that, when the target market has information asymmetry, its participants present "herd behavior". This phenomenon is particularly obvious in the Chinese P2P lending market with lack of platform transparency. In the early stage of the P2P lending industry in China, the popularity of the platform had a high appeal to investors because they were generally unprofessional. Many platforms used high returns to attract investors. With the outbreak of the vicious incidents in 2015, the investment behavior became more rational, and the influence of the platform on investment behavior began to weaken gradually.

Although the impact of popularity on investment behavior is declining, its influence on the operation ability of the platform is straightforward. The three dimensions of operational ability in the Chinese P2P lending industry, namely volume, activity and cash flow, are closely linked to the popularity of the platform. A platform with high popularity will effectively improve the market's evaluation of its operating ability. Therefore, based on the above analysis, the following hypothesis is put forward:

Hypothesis 8 (H8). The popularity of a P2P lending platform has a positive influence on the operation ability of $P 2 P$ lending platform. The high popularity will enhance the platform's volume, activity and cash flow, which are important dimensions of operational capability.

Based on the above hypotheses, we illustrate the influence factors of investment platform selection in the Chinese P2P lending market, from the investor's perspective in Figure 2. The model consists of six variables: operation ability, profitability, popularity, platform resources, security, and investment behavior.

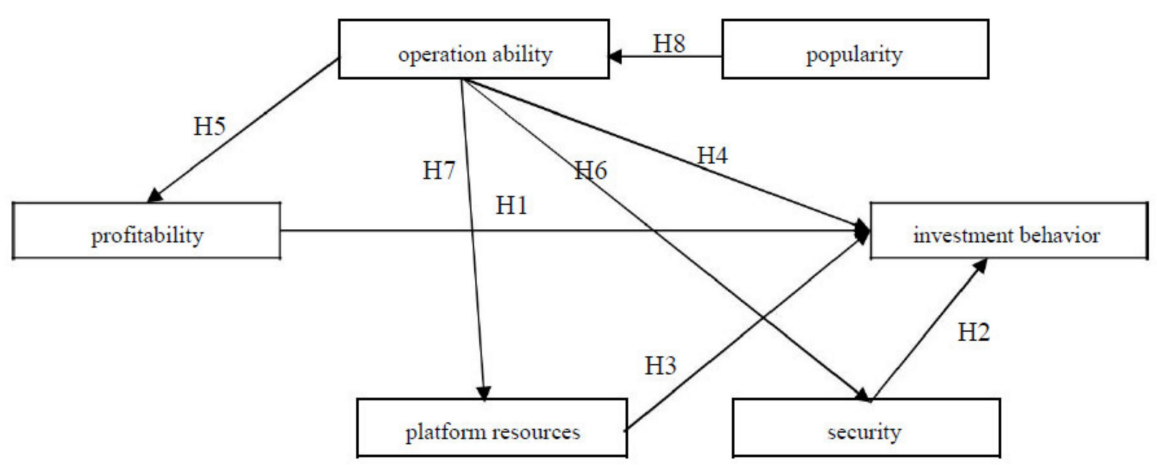

Figure 2. The influence factors of investment platform selection. 


\section{Empirical Analysis}

\subsection{Descriptive Statistical Analysis}

The descriptive statistics of 82 sample platforms are presented in Tables 9 and 10. Half of these platforms have operated for more than three years, and the private-owned platforms account for the largest proportion (60\%). There are huge differences in the operational capacity of P2P lending platforms in China, which is extremely unbalanced, with less than $20 \%$ of platforms being well run. It is especially worth noting that 57 platforms, almost $70 \%$ of the sample, have more than ten times leverage, which suggests that most of the P2P lending platforms have some operation problems. In the variables reflecting the profitability, the average interest rate of all the $\mathrm{P} 2 \mathrm{P}$ lending platforms is $11 \%$, and nearly $70 \%$ of $\mathrm{P} 2 \mathrm{P}$ lending platforms have an interest rate of over $10 \%$, which indicates that the industry still has high investment value. From the variables reflecting the popularity, the investors still have relatively high investment behavior; however, most investors tend to be rational in choosing P2P lending platforms. The concentration of the industry has increased and the gaps between the P2P lending platforms have enlarged. In terms of platform resources, the P2P lending industry is still mainly invested in using private capital, while, along with improving industry formalization, capital sources such as state-, bank- and listed-company-owned capital are flowing into the industry. In respect of security, there is a lack of capital deposit and credit collection in the Chinese P2P lending industry and the penetration rate is less than $20 \%$.

Table 9. Descriptive statistics (a).

\begin{tabular}{|c|c|c|c|c|c|c|c|}
\hline Variable & Standard & Amount & Proportion & Variable & Standard & Amount & Proportion \\
\hline Background & 1 & 52 & $63.41 \%$ & Object Time (Minute) & $>720$ & 17 & $20.73 \%$ \\
\hline Bank Depository & 1 & 16 & $19.51 \%$ & Leverage & $>10$ & 57 & $69.51 \%$ \\
\hline ICP License & 1 & 36 & $43.9 \%$ & Operation Time (Month) & $>36$ & 41 & $50 \%$ \\
\hline Venture Capital & 1 & 34 & $41.46 \%$ & Final Maturity (Month) & $>6$ & 30 & $36.59 \%$ \\
\hline Guild & 1 & 40 & $48.78 \%$ & Registered Capital (Billion) & $>0.1$ & 34 & $41.46 \%$ \\
\hline Public Equity & 1 & 20 & $24.39 \%$ & Pending Loan (Billion) & $>5$ & 16 & $19.51 \%$ \\
\hline Third-Party Credit & 1 & 11 & $13.41 \%$ & Time Weighted Volume (Billion $\times$ Month) & $>10$ & 17 & $20.73 \%$ \\
\hline Volumes (Billions) & $>1$ & 16 & $19.51 \%$ & Pending Loan For 60 Days (Billion) & $>1$ & 23 & $28.05 \%$ \\
\hline Investor & $>30,000$ & 21 & $25.61 \%$ & Top 10 Investment Proportion & $>0.2$ & 15 & $18.29 \%$ \\
\hline Borrower & $>20,000$ & 13 & $15.85 \%$ & Top 10 Loan Proportion & $>0.2$ & 41 & $50 \%$ \\
\hline Rate & $>0.1$ & 54 & $65.85 \%$ & Per Capita Loan (Million) & $>1$ & 38 & $46.34 \%$ \\
\hline Object Quantity & $>100,000$ & 10 & $12.20 \%$ & Per Capita Investment (Million) & $>0.1$ & 11 & $13.41 \%$ \\
\hline
\end{tabular}

\subsection{Model Evaluation and Parameter Estimation}

Using the PCA Equation (1), the values of the five influencing factors were calculated. Then, the structural equation model was used to examine the relationship between the five influencing factors and the investors' investment behavior. The results are shown in Table 11. All indexes met the general evaluation criteria and the model fits well. The estimated results of the parameters are shown in Table 12, and the path coefficients between variables are significant. Six of the eight hypotheses were verified, and two were not. The standardized structure diagram is shown in Figure 3. 
Table 10. Descriptive statistics (b).

\begin{tabular}{cccccccc}
\hline Variable & Max. & Min. & AVG & Variable & Max & Min & AVG \\
\hline Volumes (Billions) & 14.29 & 0.02 & 0.94 & Final Maturity (Month) & 37.08 & 0.58 & 7.69 \\
\hline Investor & 156,687 & 176 & $24,513.8$ & Registered Capital (Billion) & 0.86 & 0.06 & 0.1 \\
\hline Borrower & 297,731 & 2 & $14,863.7$ & Pending Loan (Billion) & 79.05 & 0.02 & 4.49 \\
\hline $\begin{array}{c}\text { Object Time } \\
\text { (Minutes) }\end{array}$ & $30,004.2$ & 0.04 & 1002.02 & Time Weighted Volume (Billion × Month) & 209.12 & 0.04 & 8.36 \\
\hline $\begin{array}{c}\text { Operation Time } \\
\text { (Months) }\end{array}$ & 111 & 21 & 40.17 & Pending Loan For 60 Days (Billion) & 9.96 & 0.04 & 1 \\
\hline Rate & 0.22 & 0.05 & 0.11 & Top 10 Investment Proportion & 0.99 & 0.01 & 0.13 \\
\hline Leverage & 650.43 & 0.29 & 63.04 & Top 10 Loan Proportion & 1 & 0.01 & 0.27 \\
\hline Object Quantity & $5,844,116$ & 33 & 135,656 & Per Capita Loan (Thousand) & 232,047 & 3.7 & 7599.6 \\
\hline & & & & Per Capita Investment (Thousand) & 6439.1 & 1.3 & 196.7 \\
\hline
\end{tabular}

Table 11. Model suitability value.

\begin{tabular}{ccccccc}
\hline$\chi 2 / d f$ & GFI & AGFI & NFI & IFI & CFI & RMSEA \\
\hline 1.642 & 0.950 & 0.947 & 0.970 & 0.976 & 0.976 & 0.021 \\
\hline
\end{tabular}

Table 12. Hypothesis and significance test.

\begin{tabular}{ccccccc}
\hline Hypotheses & $\begin{array}{c}\text { Standardized } \\
\text { Coefficients }\end{array}$ & $\begin{array}{c}\text { Unstandardized } \\
\text { Coefficients }\end{array}$ & Std Dev & T & $p$ & Result \\
\hline Investment behavior $<$ profitability & 0.934 & 0.152 & 0.328 & 5.41 & 0.000 & True \\
\hline Investment behavior < security & 0.438 & 0.105 & 0.021 & 4.99 & 0.000 & True \\
\hline Investment behavior $<$ platform resources & -0.253 & -0.084 & 0.028 & -3.015 & 0.003 & False \\
\hline Investment behavior < operation ability & 1.973 & 0.125 & 0.012 & 10.795 & 0.000 & True \\
\hline Profitability < operation ability & -0.842 & -0.328 & 0.015 & -21.638 & 0.000 & True \\
\hline Security < operation ability & -0.698 & -0.184 & 0.021 & -8.766 & 0.000 & False \\
\hline Platform resources $<$ operation ability & 0.213 & 0.213 & 0.082 & 2.604 & 0.009 & True \\
\hline Operation ability < popularity & 0.426 & 0.748 & 0.177 & 4.232 & 0.000 & True \\
\hline
\end{tabular}

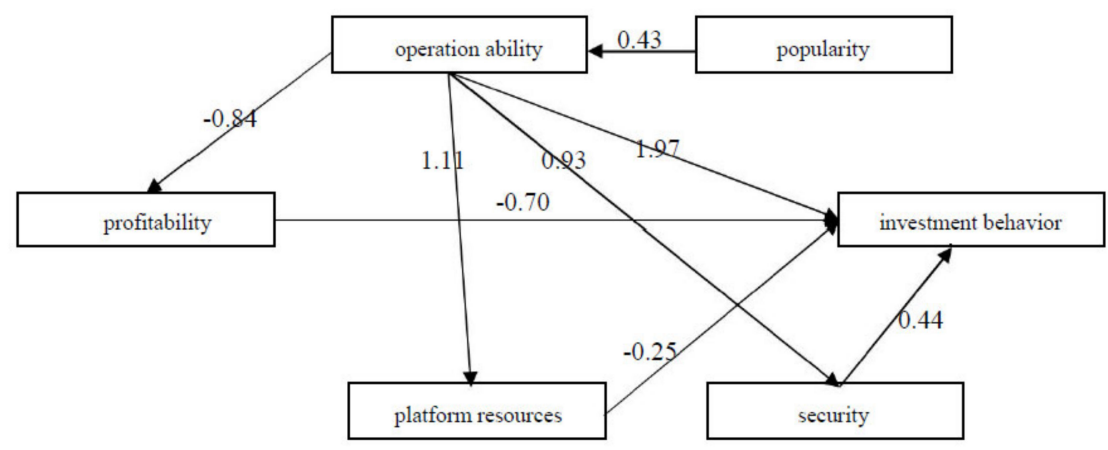

Figure 3. The standardized structure diagram.

The results show that the operation ability, profitability and security of the platform positively affect the investment behavior, and thus Hypotheses 1,2 and 4 were verified. Operation ability has the most positive impact on investment behavior $(\beta=1.973, p<0.001)$. At the same time, the operation ability 
of the platform positively affects its platform resources, and negatively impacts its profitability; thus, Hypotheses 5 and 7 were verified. The popularity of the platform has a positive impact on its operation ability; thus, Hypothesis 8 was validated. In contrast to the previous hypotheses, the platform resources negatively influence the investment behavior, while the operation ability of the platform also negatively influences its security, and both have significant $p$ values. Thus, Hypotheses 3 and 6 were not verified; instead, the opposite conclusion was drawn.

\subsection{Analysis of Research Results}

To investigate why Hypotheses 3 and 6 were not verified we needed to make an in-depth analysis of the correlation between the indicators involved. The association rule can reflect the interdependence and relevance of one thing to another. This method has a strong applicability, since it does not require the data to be continuous, obey normal distribution, satisfy the correlation test, etc. The model of association rule finds patterns in data where each entity is associated with other entities. The model constructs rule sets that define the relationships and explores more complex patterns. Association algorithms aim to find a lot of rules; each one may have its own conclusion. The best rules are stored and all rules are specialized based on various constraints, which is a process of adding conditions to a rule. These new rules are then validated against the data, and the process repeatedly stores the most interesting or best rules found.

This study analyzed the problems by association rules. Key concepts relevant to this analysis include condition support, confidence, rule support, lift, and deploy ability. Their interpretation are given in Table 13.

Table 13. Association rules index.

\begin{tabular}{|c|c|}
\hline Indicators & Explanations \\
\hline Condition support & The proportion of rule labels for which the antecedents are true. \\
\hline Confidence & The ratio of rule support to antecedent support. \\
\hline Rule support & $\begin{array}{l}\text { The proportion of rule labels for which the entire rule, antecedents, } \\
\text { and consequent are true. }\end{array}$ \\
\hline Lift & The ratio of confidence for the rule to the prior probability of having the consequent. \\
\hline Deploy ability & $\begin{array}{l}\text { The percentage of the training data satisfies the conditions of the antecedent but does } \\
\text { not satisfy the consequent. }\end{array}$ \\
\hline
\end{tabular}

\subsubsection{The Impact of Platform Resources on Investment Behavior}

In this section, we analyze the distribution of variables in the different investment behaviors of various measurement platform resources, and the results show that the variables are not normal. By using association rules to analyze investment behavior and background, and selecting investment behavior as the predictor variable, the background variables were divided into four options as the conditional variables: bank-owned platform, listed-company-owned platform, state-owned platform, private-owned platform. The assignment rules are all " 1 for yes, 0 for no", and the results are shown in Figure 4 and Table 14.

The results of the association rules in Table 14 show that investors' investment behavior is not high towards state- or private-owned platforms. Combined with Figure 4, investors' investment behavior towards bank- and listed-company-owned platforms is in line with market expectations, and the investment behavior in state-owned platforms is much less than that of the previous two. Some scholars have paid close attention to such situations. Wei et al. argued that listed companies tend to invest in platforms with mature business and good prospects for development. At the same time, those platforms invested in by listed companies can provide high quality resources based on their own industry foundation, which can 
help the platform scale growth [23]. The situation of bank-owned platforms is similar. Comparatively, the current level of development of state-owned platforms is uneven, and some of the so-called state-owned platforms only have a small amount of state capital. In addition, there are fake state-owned platforms for propaganda purposes, which leads to low level of investment behavior for state-owned platforms.

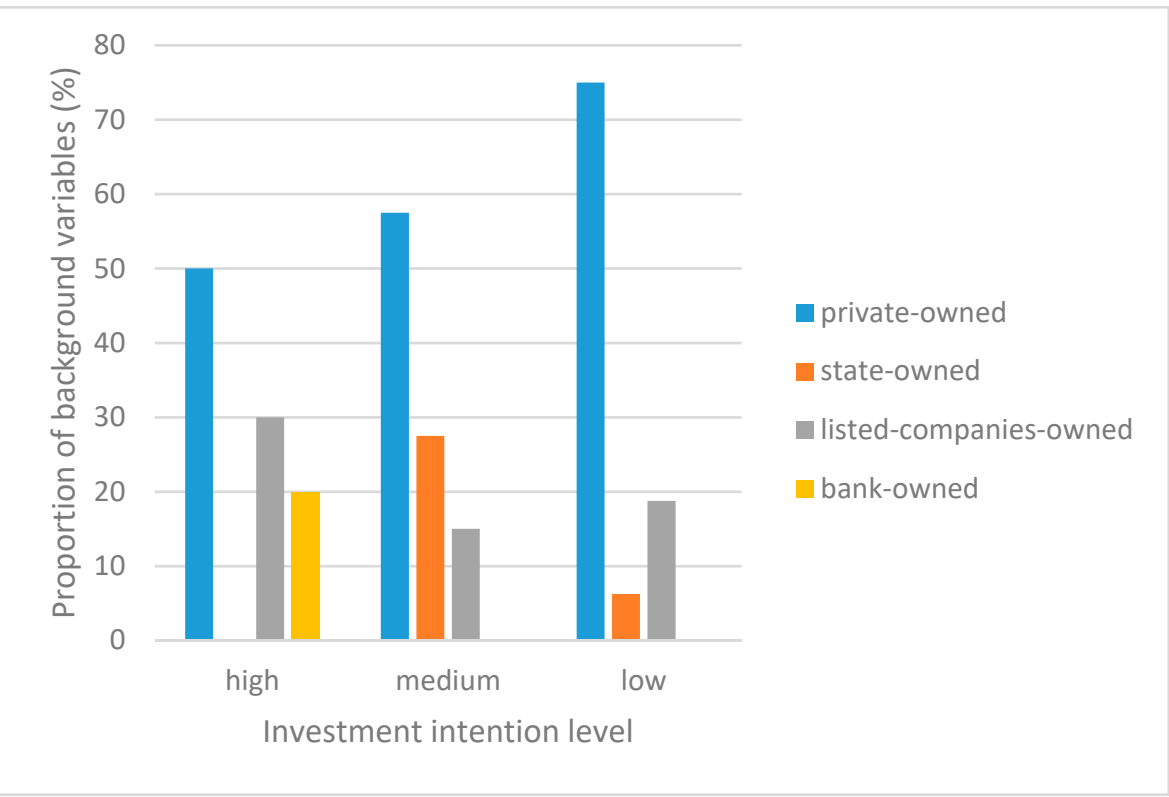

Figure 4. The distribution of background variables.

Table 14. The most relevant rules of investment behavior.

\begin{tabular}{|c|c|c|c|c|c|c|c|}
\hline Rule Label & Condition & Prediction & $\begin{array}{l}\text { Confidence } \\
(\%)\end{array}$ & $\begin{array}{l}\text { Condition } \\
\text { Support (\%) }\end{array}$ & $\begin{array}{c}\text { Rule Support } \\
(\%)\end{array}$ & Lift & $\begin{array}{c}\text { Deploy } \\
\text { Ability (\%) }\end{array}$ \\
\hline 1 & $\begin{array}{l}\text { State-owned platform }=0 \\
\text { Private-owned platform }=0\end{array}$ & $\begin{array}{c}\text { Investment } \\
\text { behavior } \geq 6\end{array}$ & 29.41 & 20.73 & 6.1 & 2.41 & 14.63 \\
\hline
\end{tabular}

The cause of this phenomenon, on the one hand, may be that the state-owned platforms' profitability is relatively low, and in terms of security there are no obvious advantages over bankand listed-company-owned platforms, which seriously affects the enthusiasm of investors to invest. On the other hand, due to the current regulatory mechanism for P2P platforms, information disclosure is not yet perfect, and some platforms may deliberately exaggerate their own domestic share. Thus, the market begins to doubt the true quality of state-owned platforms, and thus affect investors' overall trust in them.

\subsubsection{The Impact of Operation Ability on Security}

To investigate why Hypothesis 6 was not verified, we used K-means to divide the operation ability of the sample into three levels, assigning them to 3, 2, and 1 from high to low, respectively. Then, we used association rules to analyze operation ability and the three variables measuring the security of the platform (bank depository, guild, and third-party credit). The operation ability was selected as the predictor variable, while bank depository, guild, and third-party credit were the condition variables. The results are shown in Tables 15 and 16 and Figure 5. 
Table 15. The classification results of operation ability.

\begin{tabular}{cccc}
\hline & \multicolumn{4}{c}{ Cluster } \\
\hline Cluster center & $\mathbf{1}$ & $\mathbf{2}$ & $\mathbf{3}$ \\
\hline Sample size & 71.82 & 29.66 & -8.45 \\
\hline
\end{tabular}

Table 16. The most relevant rules of operation ability.

\begin{tabular}{|c|c|c|c|c|c|c|c|}
\hline Rule Label & Condition & Prediction & $\begin{array}{c}\text { Confidence } \\
(\%)\end{array}$ & $\begin{array}{c}\text { Condition } \\
\text { Support (\%) }\end{array}$ & $\begin{array}{c}\text { Rule Support } \\
(\%)\end{array}$ & Lift & $\begin{array}{c}\text { Deploy } \\
\text { Ability (\%) }\end{array}$ \\
\hline 1 & $\begin{array}{l}\text { Bank depository }=0 \\
\text { third-party credit }=1\end{array}$ & $\begin{array}{l}\text { Operation } \\
\text { ability }=3\end{array}$ & 71.43 & 8.54 & 6.1 & 3.45 & 2.44 \\
\hline 2 & $\begin{array}{l}\text { Guild = } 1 \text { third } \\
\text { Party credit }=1\end{array}$ & $\begin{array}{l}\text { Operation } \\
\text { ability }=3\end{array}$ & 55.56 & 10.98 & 6.1 & 2.68 & 4.88 \\
\hline 3 & Third-party credit $=1$ & $\begin{array}{l}\text { Operation } \\
\text { ability }=3\end{array}$ & 54.55 & 13.41 & 7.32 & 2.63 & 6.1 \\
\hline 4 & $\begin{array}{c}\text { Bank depository }=0 \\
\text { Guild }=1\end{array}$ & $\begin{array}{l}\text { Operation } \\
\text { ability }=3\end{array}$ & 42.86 & 34.15 & 14.63 & 2.07 & 19.51 \\
\hline
\end{tabular}

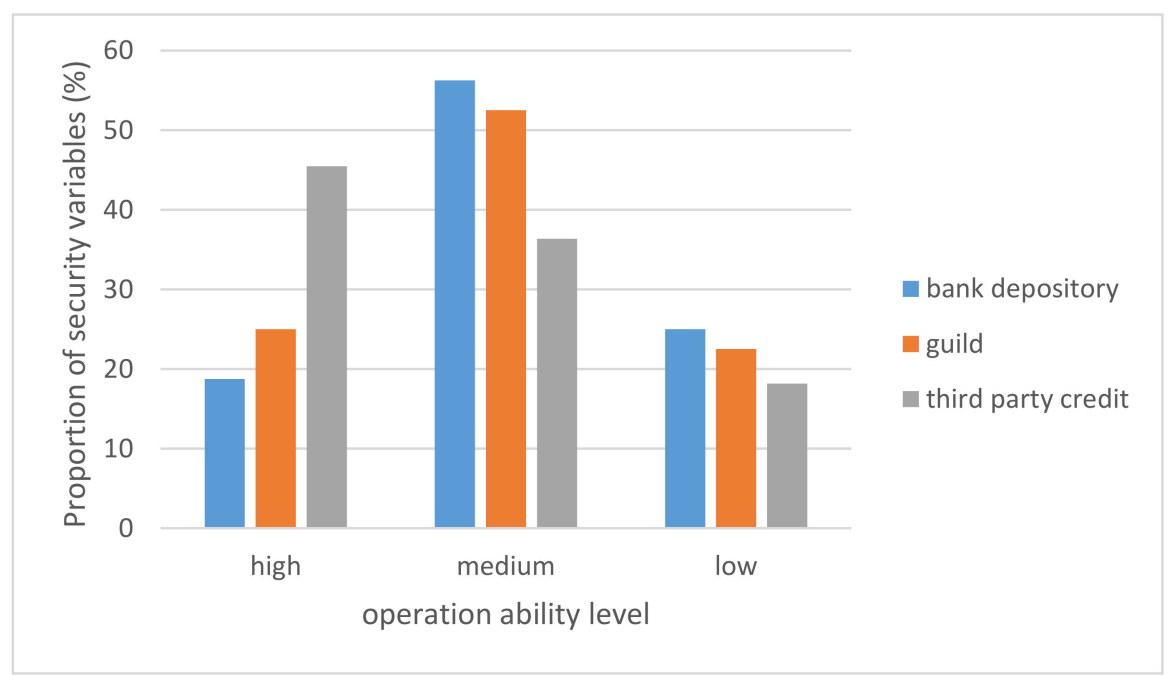

Figure 5. The distribution of security variables.

The results of the association rules in Table 16 show that most of the platforms with strong operation ability have carried out third-party credit businesses and joined guilds. In the case of bank depository, however, there is little business in the bank depository. Combined with the results in Figure 5, it is clear that, in the Chinese P2P lending industry, the platforms with strong operation ability mainly rely on third-party credit to enhance their security, while lack bank depository business. On the one hand, it may be due to the lack of a perfect personal credit system in China. For P2P lending platforms, they confront a high technical threshold when constructing their own personal credit system, and need to invest too much in risk identification, which can greatly reduce the benefits of the platforms. Therefore, it is the most cost-effective option to cooperate with third-party credit information organizations. On the other hand, since banks have a threshold for docking access, there are certain rules and regulations regarding the platforms' qualification and compliance, which will take a lot of resources from P2P lending platforms to make adjustments. 
For investors, the impact of bank depository on their investment behaviors towards a platform is also increasingly important. After the relevant policies have been issued, the platforms with strong operation ability also carry out docking with banks actively for capital depository to improve the security of the platforms, so as to attract more investors. However, in the current P2P lending market in China, the platforms need to pass a series of investigations by banks to realize the docking of capital depository. This has certain requirements on the technical level of the platforms, and requires substantial investments, which directly leads to the slow progress of the access to bank depository for current platforms. Currently, less than $5 \%$ of the industry has bank depository system and is the main reason for this anomaly.

\section{Discussion}

Based on the above analysis, this paper provides the following suggestions for market participants. The P2P lending platforms should pay more attention to the improvement of operation ability and enhance the ability of risk control when planning for future, since it is difficult to rely only on improving profitability to attract investors in the current Chinese P2P lending market. Due to the imperfect market and lack of a credit information system, platform risk is the main risk type in the P2P lending industry in China, and the moral hazard is obviously higher than the operational risk. From a moral hazard point of view, higher returns often imply a higher risk. After experiencing a series of risk events, the P2P lending industry's overall profitability has become more rational, and investors are no longer blindly pursuing high yield and high popularity but pay more attention to the platforms themselves. From the perspective of operational risk, this is because of the immature development of the P2P lending market in China; those platforms with greater strength and complete risk control tend to have stronger risk tolerance and will receive more attention from investors. From the results of the study, a platform with strong operation ability will reduce the risks faced by investors at all levels, and a poorly run platform will magnify the risk.

The competition pattern of the Chinese P2P lending industry is preliminarily formed. Competent platforms have matured in external resources development, internal management, capital and technical strength. For investors, choosing a competent platform to invest can maximize the security of funds. They can also choose to invest in a combination of investments based on their own demand for profitability, while pursuing profit maximization and reducing risk further.

Whether the P2P lending platform owns the bank depository business is the most effective indicator for investors to evaluate the platform's safety. Investors should try to invest in the P2P lending platforms with completed capital depository in a bank, and verify that the platform is in accordance with relevant policies. For investors, whether the platform has the capital depository business is not just a matter of financial security, it can also reflect the comprehensive strength and technical level of the platform due to the restrictions of banks on capital depository. In choosing the platform for cooperation, a bank mainly considers three aspects. The first is the credibility of the P2P lending platform. Since a bank taking over the capital depository of the platform is equivalent to the credit endorsement, the bank generally requires the cooperated platforms have the background of state or public company, platform executives have experiences in the financial industry, etc., to avoid the negative impact of the platform's bad news on the creditworthiness of the bank. The second is the volume of the platform. A bank requires the transaction amount of the platform reach a certain level and sets different depository rates depending on the size of the platform. The corresponding depository rate of the large-volume platforms can be appropriately reduced, while the smaller platforms will be charged a higher depository rate; thus, the cost of bank depository can reach an expected level. The last point is the technical aspect. Both the bank and the P2P lending platform need to have certain technical capabilities if they plan to develop a sophisticated system of depository technology. This usually takes a bank great time and funds, and high technical cost, which also puts off many less powerful platforms. 
The results show that the number of platforms with capital depository in bank is very limited. These platforms have very high investment value for investors, considering its capital security or platform resources. With a series of regulatory policies in China, many rules, including the mandatory requirements for bank depository, have put enormous pressure on the entire P2P lending industry. Many weak platforms have difficulty fully meeting the requirements of regulation during the rectification period; excessive compliance costs will bring a significant cost burden for them, and the future profit space will be substantially compressed. Thus, most of these platforms will therefore exit the P2P lending market. Investors should also pay attention to the direction of relevant policies when choosing platforms for investment, and ensure that they have no problems in compliance.

The P2P lending platforms with abundant resources have a good investment prospect, especially the bank- and listed-company-owned platforms. From the initial formation of the P2P lending industry, capital has nearly completed the layout of the P2P lending industry in China. Large platforms have more advantages in attracting users and talent, while smaller platforms are less likely to gain new investment unless they have innovative assets or models. Therefore, the platforms with strong resources not only have strong capital strength, but also often have strong operation ability, high technical level, and a good development prospect. In addition, because of the huge information asymmetry between investors and platforms, platform resources also represent an important criterion based on which the investors can judge the platforms.

In our study, we also found that there are some operational problems in the state-owned platforms, which cause the lack of competitiveness in terms of safety and profitability compared to the bank- and listed-company-owned platforms, and the investment behavior on the state-owned platforms is weaker than that of the other two types of platforms. In addition, the current state-owned platforms obtain assets through cooperation with other asset providers, such as financing guarantee companies, small loan companies, factoring companies, financial asset exchange, etc. The bid price is often very high, which is less attractive to individual investors. Under the premise of risk control, investors can invest more in the bank- and listed-company-owned platforms to pursue higher ROI.

\section{Conclusions}

From the investor's perspective, this paper discusses five factors that influence investors' investment behavior as well as the relationships among them. The results show that the investment behavior of investors is in line with the general rules of industry investment and has some other characteristics because of the development level and the particularity of the Chinese P2P lending market, such as paying special attention to the platform background. Based on our study, we found that the operation ability of platform is not only the main consideration factor when investors choose platform for investment, but also profoundly influences the other factors. Platforms with strong operational capabilities tend to have more reasonable profitability and are more attractive for capital with a strong background. For investors, relatively high yields are still appealing; however, there are some doubts in making investment decisions because of a series of risk problems in the Chinese P2P lending market, and their investment behavior has become more rational. Instead of simply chasing high-yielding and popular platforms, investors are more likely to consider the platform's operation ability and security, and make judgments based on comprehensive factors. In terms of platform resources, investors will still give priority to the P2P lending platforms with strong background. Since state-owned platforms have many problems, and there are no obvious advantages in terms of security and profitability compared to bank- and listed-company-owned platforms, the investment behavior of investors on state-owned platforms is not as strong as on the other two types of platforms. 
Although the current industry is still facing many problems in the development of the Chinese market and has made many changes in order to survive, as long as the market demand still exists, $\mathrm{P} 2 \mathrm{P}$ lending platforms will continue to exist in various forms. The requirements of P2P lending platforms for high-level risk control technologies also determines their future development and will inevitably lead to intensification, which has also been confirmed in the development history of the P2P lending industry in developed countries. In the process of the development of the P2P lending industry in China, the government has also become deeply involved in it gradually, with an increasing influence. However, based on the current development status of the industry in China, the attitude of supervision is very contradictory. On the one hand, the government hopes that the P2P lending industry will play an active role in addressing social financing needs; on the other hand, it also shows a deep concern about the risk caused by its inadequate level of risk control. In general, the government encourages top platforms with the strength to explore development models suitable for the Chinese market and provides targeted policy support to a certain extent. For example, more than 20 online lending platforms that meet the requirements are connected to the credit information system of the central bank. Investors' investment in these platforms is also guaranteed to a certain extent. In the future research on the P2P lending industry in China, the attitude of the government is a key point that must be addressed directly. This has quite high research value and is a research direction with great potential.

Author Contributions: X.Y. conceived the study and drafted the manuscript. W.F. carried out the computer programming and participated in the data analysis. S.Y. participated in its design and coordination and helped to draft the manuscript. All authors have read and agreed to the published version of the manuscript.

Funding: This work was supported by the National Natural Science Foundation of China [project No.71490720 and No.41661116].

Conflicts of Interest: All authors declare no conflict of interest.

Availability of Data and Materials: In this paper, all data were collected from the Chinese P2P lending industry rating report and the two main third-party information platforms which rate P2P lending platforms in Chinese P2P lending market, WDJZ and P2Peye. As for the issue of individual privacy, the data should not be shared in the paper.

\section{References}

1. MacQueen, J. Some Methods for Classification and Analysis of Multivariate Observations. In Proceedings of the Fifth Berkeley Symposium on Mathematical Statistics and Probability, Berkeley, CA, USA, 27 December 1965; pp. 281-297.

2. Hartigan, J.A.; Wong, M.A. Algorithm AS 136: A K-means clustering algorithm. Appl. Stat. R. Stat. Soc. 1979, 28, 100-108. [CrossRef]

3. Kumar, V.L.; Natarajan, S.; Keerthana, S.; Chinmayi, K.M.; Lakshmi, N.S. Credit Risk Analysis in Peer-To-Peer Lending System. In Proceedings of the 2016 IEEE International Conference on Knowledge Engineering and Applications (Ickea 2016), Singapore, 28-30 September 2016; pp. 193-196.

4. Guo, Y.; Zhou, W.; Luo, C.; Liu, C.; Xiong, H. Instance-Based Credit Risk Assessment for Investment Decisions in P2p Lending. Eur. J. Oper. Res. 2016, 249, 417-426. [CrossRef]

5. Serrano-Cinca, C.; Gutierrez-Nieto, B. The Use of Profit Scoring as an Alternative to Credit Scoring Systems in Peer-to-Peer (P2P) Lending. Decis. Support Syst. 2016, 89, 113-122. [CrossRef]

6. Xia, Y.; Liu, C.; Liu, N. Cost-Sensitive Boosted Tree for Loan Evaluation in Peer-to-Peer Lending. Electron. Commer. Res. Appl. 2017, 24, 30-49. [CrossRef]

7. Puro, L.; Teich, J.E.; Wallenius, H.; Wallenius, J. Borrower Decision Aid for People-to-People Lending. Decis. Support Syst. 2010, 49, 52-60. [CrossRef]

8. Tan, F.; Hou, X.; Zhang, J.; Wei, Z.; Yan, Z. A Deep Learning Approach to Competing Risks Representation in Peer-to-Peer Lending. IEEE Trans. Neural Netw. Learn. Syst. 2018, 30, 1-10. [CrossRef] [PubMed] 
9. Jiang, Y.; Ho, Y.C.; Yan, X.; Tan, Y. Investor Platform Choice: Herding, Platform Attributes, and Regulations. J. Manag. Inf. Syst. 2018, 35, 86-116. [CrossRef]

10. Yum, H.; Lee, B.; Chae, M. From the Wisdom of Crowds to My Own Judgment in Microfinance through Online Peer-to-Peer Lending Platforms. Electron. Commer. Res. Appl. 2012, 11, 469-483. [CrossRef]

11. Emekter, R.; Tu, Y.; Jirasakuldech, B.; Lu, M. Evaluating Credit Risk and Loan Performance in Online Peer-To-Peer (P2p) Lending. Appl. Econ. 2015, 47, 54-70. [CrossRef]

12. Shen, F.; Luo, N. Investment Pattern Clustering Based on Online P2p Lending Platform. In Proceedings of the 2016 IEEEACIS 15th International Conference on Computer and Information Science (ICIS), Okayama, Japan, 26-29 June 2016; pp. 181-186.

13. Zhang, Y.; Wang, X.; Qian, Y.; Jia, H. The Research of Recommendation Algorithms in P2p Lending. Mech. Control Electr. Mechatron. Inf. Comput. 2016, 241-247. [CrossRef]

14. Xu, J.; Chen, D.; Chau, M. Identifying Features for Detecting Fraudulent Loan Requests on P2p Platforms. In Proceedings of the IEEE International Conference on Intelligence and Security Informatics: Cybersecurity and Big Data, Tucson, AZ, USA, 28-30 September 2016; pp. 79-84.

15. Lin, M.; Prabhala, N.R.; Viswanathan, S. Judging Borrowers by the Company they Keep Friendship Networks and Information Asymmetry in Online Peer-To-Peer Lending. Manag. Sci. 2013, 59, 17-35. [CrossRef]

16. Liu, D.; Brass, D.; Lu, Y.; Chen, D. Friendships in Online Peer-to-Peer Lending: Pipes, Prisms, and Relational Herding. Mis Q. 2015, 39, 729-742. [CrossRef]

17. Jiang, Z.; Zou, D.; Feng, Y. Research on Attribute-Based Trust Elevation Problems in P2p Environment. Int. J. Pattern Recognit. Artif. Intell. 2011, 25, 943-952. [CrossRef]

18. Guo, G.; Zhu, F.; Chen, E.; Liu, Q.; Wu, L.; Guan, C. From Footprint to Evidence: An Exploratory Study of Mining Social Data for Credit Scoring. ACM Trans. Web 2016, 10, 22.1-22.38. [CrossRef]

19. Chen, X.; Zhou, L.; Wan, D. Group Social Capital and Lending Outcomes in the Financial Credit Market: An Empirical Study of Online Peer-to-Peer Lending. Electron. Commer. Res. Appl. 2016, 15, 1-13. [CrossRef]

20. Wang, M.; Zheng, X.; Zhu, M.; Hu, Z. P2p Lending Platforms Bankruptcy Prediction Using Fuzzy SVM with Region Information. In Proceedings of the 2016 IEEE 13th International Conference on E-Business Engineering (ICEBE), Macao, China, 4-6 November 2016; pp. 115-122.

21. Pingfan, S.; Yunzhi, C.; Zhixiang, Z.; Wu, H. Performance Analysis of Peer-to-Peer Online Lending 15platforms in China. Sustainability 2018, 10, 2987.

22. Xu, Y.; Luo, C.; Chen, D.; Zheng, H. What Influences the Market Outcome of Online P2p Lending Marketplace? A Cross-Country Analysis. J. Glob. Inf. Manag. 2015, 23, 23-40. [CrossRef]

23. Peng-Fei, W. The Characteristics of P2p Platforms and the Choice of Investors. China Bus. Mark. 2016, 12, 92-99.

24. Wei, Q.; Zhang, Q. P2p Lending Risk Contagion Analysis Based on A Complex Network Model. Discret. Dyn. Nat. Soc. 2016, 2016, 1-8. [CrossRef]

25. Rong360. The Chinese P2p Lending Industry Rating Report. Available online: https://www.r360insights. com/insights/webDateDecode/dataDecodeMore?typeId=280\&type1=\%E7\%A0\%94\%E7\%A9\%B6\&type2= $\%$ E7\%90\%86\%E8\%B4\%A2\&module_title=\%E4\%B8\%93\%E9\%A2\%98\%E6\%8A \%A5\%E5\%91\%8A (accessed on 23 January 2016). 